\title{
A Voz Verbal e o Fluxo Informacional do Texto*
}

\author{
(Verb Voice and Text Informational Flow)
}

Helena Feres HAWAD

(UERJ)

Resumo: A gramática tradicional do português postula duas formas de "voz passiva": as chamadas "analítica" e "sintética". O emprego dessas estruturas em textos sugere que elas não são diferentes realizações léxico-gramaticais do mesmo significado. No que diz respeito aos conteúdos semânticos relacionados à metafunção textual da abordagem sistêmico-funcional, elas representam contribuições distintas ao fluxo informacional dos textos. A "voz passiva analítica", que apresenta o participante paciente de um processo como Tema não-marcado, funciona principalmente como um recurso para manter o tópico discursivo, bem como para variar o grau de focalização conferido ao Agente. A "voz passiva sintética", por outro lado, na ordem não-marcada, confere proeminência temática ao Processo, ao mesmo tempo em que o participante paciente, posicionado no Rema, tende a corresponder a informação nova.

PalaVRas-Chave: Voz passiva; Clítico "se"; Tema; Dado e Novo.

ABSTRACT: Portuguese traditional grammar postulates two forms of "passive voice", known as "analytical" and "synthetic". The use of these structures in texts suggests that they are not different lexicogrammatical realizations of the same meaning. Concerning the semantic contents related to the textual metafunction in the systemic-functional approach, they represent distinct contributions to the informational flow of the text. "Analytical passive voice", which presents the patient participant of a process as unmarked Theme, functions mainly as a resource for maintaining the topic of discourse, as well as for varying the degree of focusing on the Agent. "Synthetic passive voice", on the other hand, in its unmarked order, attaches thematic prominence to the Process, at the same time as the patient participant, placed in the Rheme, tends to correspond to new information.

KEY-Words: Passive voice; Clitic "se"; Theme; Given and New.

\footnotetext{
* Este artigo é uma versão modificada de um capítulo de minha tese de doutorado.
}

D.E.L.T.A., 20:1, 2004 (97-121) 


\section{Introdução}

A tradição gramatical da língua portuguesa postula uma sinonímia entre a voz passiva, construída com verbo auxiliar e particípio, e a construção de verbo transitivo direto com o clítico se (aqui designadas respectivamente, para facilidade de referência, como VPA, de "voz passiva analítica", e VPS, de "voz passiva sintética", não obstante a impropriedade da nomenclatura tradicional). Muitos trabalhos já questionaram essa suposta equivalência, demonstrando, em diversas linhas de argumentação, que as duas estruturas têm significados distintos, além de suas óbvias diferenças formais.

Referindo-se à voz passiva em inglês, THOMPSON (1996: 82) afirma:

Passive clauses are, of course, marked in relation to active clauses (that is, there is usually a particular reason for choosing a passive clause, whereas an active clause is the natural choice when there are no particular reasons for not choosing it) (... $)^{1}$

Parte-se, aqui, do pressuposto de que o mesmo se verifica em português, no que se refere à escolha entre voz ativa (VA), VPA e VPS. A fim de determinar as razões que motivariam a escolha de VPA ou VPS, é necessário explicitar o que as diferencia semanticamente. Neste artigo, examina-se um aspecto específico dessa distinção: a funcionalidade de cada uma das estruturas na realização do fluxo informacional dos textos. No quadro teórico sistêmico-funcional, tal funcionalidade (vista como incorporada ao próprio significado das formas léxico-gramaticais) relaciona-se a conteúdos da metafunção textual - um dos três subcomponentes do componente semântico, ao lado da ideacional e da interpessoal (cf. HALLIDAY 1994; THOMPSON 1996).

Os dados aqui analisados foram extraídos de 36 notícias e 56 textos argumentativos (entre editoriais e artigos de opinião) publicados no Jornal do Brasil entre março de 2001 e julho de 2002, em 17 edições escolhidas aleatoriamente. Foram coletadas 132 ocorrências de VPA nas notícias e 120 ocorrências de VPS nos textos argumentativos. A opção por trabalhar

1 Orações passivas, é claro, são marcadas em relação a orações ativas (ou seja, há geralmente uma razão particular para escolher uma oração passiva, enquanto uma oração ativa é a escolha natural quando não há razões particulares para não escolhê-la) (...). 
com cada estrutura em um dos grupos de textos- se deve ao fato de que VPS é praticamente inexistente nas notícias (cf. HAWAD 1999). As ocorrências foram analisadas em função de seus respectivos contextos, buscando-se determinar a relação entre a estrutura temática das orações e a codificação de informação dada e informação nova.

VA (na ordem não-marcada S V O) caracteriza-se pela coincidência das funções de Tema (textual), Agente (ideacional) e Sujeito (interpessoal) num mesmo constituinte sintático. Esse fato se reflete na concorrência de três definições tradicionais de "sujeito", que têm sido apontadas como exemplo da inconsistência da gramática tradicional (cf. PERINI 1885). HALLIDAY - (1994: 32) chama a atenção para as designações tradicionais de "sujeito psicológico", "sujeito lógico" e "sujeito gramatical", as quais, afirma, não se referem a "três espécies de alguma coisa", mas a três coisas bem diferentes. Aproximada e simplificadamente, é possível estabelecer as seguintes correlações entre as definições tradicionais de "sujeito" e as funções estruturais de HALLIDAY:

a. "Sujeito" é o termo sobre o qual se faz uma declaração - noção correlata a Tema (definido como o ponto de partida da mensagem);

b. "Sujeito" é o ser que pratica a ação verbal - noção correlata a Agente (definido como o participante que desencadeia o processo verbal), e

c. "Sujeito" é o termo com o qual o verbo concorda - noção correlata a Sujeito (redefinido em perspectiva semântica, tomado como o responsável pela validade da proposição).

Considerando-se sempre a ordem não-marcada de constituintes em cada estrutura, VPA apresenta-se, assim, como um recurso léxico-gramatical para desvincular as funções de Sujeito e Tema, de um lado, da função de Agente, de outro. Representa desse modo, simultaneamente, um meio para tematizar o Objeto ("Goal", na terminologia de HALLIDAY), que é o participante paciente de um processo verbal, e uma possibilidade de exprimir um Processo sem a especificação do Agente. Esses dois aspectos constituem dois traços do significado de VPA - relacionados, porém distintos. VPS, por outro lado, oferece a possibilidade de exprimir um Processo sem a especificação do Agente, mas não a possibilidade de tematizar 
o Objeto, uma vez que, na ordem não-marcada, é o Processo que ocupa a posição temática - a primeira posição oracional. ${ }^{2}$

Numa primeira análise global dos dados, contagens manuais e cálculo de porcentagens revelaram que, em cerca de $77 \%$ das ocorrências de VPA no corpus, o Objeto (função ideacional coincidente, em VPA, com a função interpessoal de Sujeito) é um elemento Dado no desenvolvimento do texto - ou seja, o Objeto de VPA, na maioria dos casos (102 no total de 132), é um termo com valor remissivo, ou anafórico. Nas ocorrências de VPS, por outro lado, isso só se verifica em cerca de $27 \%$ dos casos, ou seja, na minoria deles (32 no total de 120).

Essa primeira verificação quantitativa favorece a hipótese de que a tematização do Objeto, como forma de codificar o Dado na primeira posição oracional, é uma importante motivação para o emprego de VPA. THOMPSON (1996: 130), a propósito, observa:

(...) we should mention one structural resource which has a number of functions including that of moving a particular constituent into Theme. This is passivisation. In most cases, there will be a complex web of reasons for choosing passive rather than active; but there are some cases where the influence of Theme choice is relatively dominant. This is clearest where the Agent (the 'doer' of the action) is explicitly mentioned in a prepositional phrase with 'by', since in these cases both potential Subjects are present. ${ }^{3}$

O emprego de VPA com a finalidade de tematizar o Objeto cumpre, portanto, uma das tarefas funcionais reconhecidas do Tema: a de contribuir para a continuidade do Tópico do discurso (cf. GÓMEZ-GONZÁLEZ 2000: 97-98), facilitando o processamento cognitivo do texto (cf. KOPPLE 1986).

A essa análise quantitativa inicial, seguiu-se a análise qualitativa das ocorrências em contexto, da qual resultou um quadro mais detalhado das

2 A questão da ordem não-marcada e da estrutura temática em VPS é discutida no capítulo 2 e na seção 3.1.2 de minha tese.

3 (...) devemos mencionar um recurso estrutural que tem várias funções, incluindo a de mover um constituinte particular para o Tema. É a passivização. Na maioria dos casos, há uma rede complexa de razões para escolher a passiva em vez da ativa; mas há alguns casos em que a influência da escolha do Tema é relativamente dominante. Isso é mais claro quando o Agente ("aquele que faz" a ação) é explicitamente mencionado num sintagma preposicional com "por", uma vez que, nesses casos, ambos os Sujeitos potenciais estão presentes. 
diferenças semântico-funcionais entre VPA e VPS, conforme apresentado nas seções 2 e 3, abaixo.

\section{VPA: A tematização do Objeto}

O Objeto tematizado nas ocorrências de VPA no corpus realiza diversos tipos de Dado, ilustrados a seguir pela análise de algumas delas.

Há casos em que o Sujeito de VPA simplesmente faz remissão a um referente presente no co-texto precedente, seja no mesmo período, como em (1), seja em período anterior, como em (2), que aparece no último parágrafo de uma notícia em que o referente "o ex-governador do Distrito Federal Cristovam Buarque” é mencionado várias vezes desde o primeiro:

(1) Também defendeu que, se houver irregularidades, elas precisam ser investigadas.

(2) O ex-governador (...) é apontado como um dos nomes fortes (...) para as eleições (...).

Ocorrem também, no corpus, orações em que o Objeto tematizado é uma nominalização que resume eventos mencionados no co-texto precedente, como (3) e (4), abaixo:

(3) A decisão foi tomada, por unanimidade, pelos presidentes dos cinco tribunais superiores $(\ldots)$

(4) A determinação foi imediatamente cumprida pelo PSDB (...)

A análise desses casos mostra que, nas notícias jornalísticas em português, encontra-se o padrão de organização informacional baseado na função de "encapsulamento" desempenhada pelas nominalizações, conforme descrição de THOMPSON (1996: 170):

One important function of nominalisation is encapsulation. Broadly speaking, co-operative text typically introduces new meanings in the form of clauses, since clauses are negotiable (...): they represent claims by the writer which the reader can, in principle, reject. Once a meaning has been introduced in this way and has been accepted (i.e. the reader has continued reading), it can then be used as a basis for the next step in the argument. Now, nominal groups have two qualities which are useful here. First, a noun typically refers to a 'thing', i.e. something which exists. By 'nouning' a process, the writer can reflect the fact that s/be has negotiated and 
established the meaning of the clause centred around the process - in other words, that meaning can now be treated as existing, as a kind of abstract 'thing'. Second, a nominalisation is itself avaiable to function as a participant in another process. It can also, of course, function as Theme. We therefore find the fairly common pattern in formal discursive text where a meaning is brought in as a full clause, and is then encapsulated in a nominalisation which serves as the starting point for the next clause. ${ }^{4}$

Vê-se, portanto, que o emprego de VPA com nominalizações na função de Sujeito permite transformar, pela tematização de tais nominalizações, um fato complexo descrito no co-texto precedente em ponto de partida de uma nova mensagem, dando, assim, andamento ao fluxo informacional do texto. O emprego da forma ativa correspondente não possibilitaria que essas nominalizações preenchessem a função de Tema não-marcado.

No exemplo (3), é especialmente significativo o fato de que a forma perifrástica tomar decisão tenha sido escolhida em vez do Predicador decidir. Essa opção permite justamente tomar os eventos descritos anteriormente como ponto de partida da nova mensagem, o que formas alternativas com o verbo decidir não permitiriam. NEVES (2000) reconhece, entre as funções das perífrases com "verbo-suporte" (como tomar, nesse caso), as seguintes:

O uso do verbo-suporte pode representar alteração da organização informativa da oração, o que possivelmente provocará conseqüências no desenvolvimento do próprio fluxo de informação do texto. (...) a relação entre o tema e o rema (...) na oração com verbo-suporte se altera, em comparação com as construções com o verbo simples correspondente. (p.58)

O uso da construção sintática verbo-suporte + objeto permite a obtenção de efeitos na configuração textual. Pode-se, pelo emprego de construções com verbo-suporte (...), operar referenciação. (p.60)

\footnotetext{
4 Uma função importante da nominalização é o encapsulamento. Em sentido amplo, o texto cooperativo tipicamente introduz significados novos na forma de orações, uma vez que orações são negociáveis (...): elas representam asserções do escritor que o leitor pode, em princípio, rejeitar. Uma vez que um significado foi introduzido desse modo e foi aceito (i.e. o leitor continuou lendo), ele pode então ser usado como base para o próximo passo do argumento. Sintagmas nominais têm duas qualidades que são úteis aqui. Primeiro, um nome tipicamente se refere a uma "coisa", i.e. algo que existe. "Nomeando" um processo, o escritor pode refletir o fato de que ele negociou e estabeleceu o significado da oração centrada no processo - em outras palavras, que o significado pode agora ser tratado como existente, como um tipo de "coisa" abstrata. Segundo, uma nominalização é, ela mesma, passível de funcionar como um participante em outro processo. Pode também, é claro, funcionar como Tema. Então, encontramos o padrão consideravelmente comum no texto formal discursivo em que um significado é introduzido como uma oração completa, e depois é encapsulado em uma nominalização que serve como ponto de partida da próxima oração.
} 
Há ainda casos em que o Tema inclui um elemento Dado acrescido de um elemento Novo. É o que ocorre no exemplo abaixo, em que assinaturas é um referente retomado do co-texto precedente, mas o número delas é Novo:

(5) Os mais otimistas sustentam que 141 assinaturas foram alcançadas.

O mesmo ocorre em

(6) (...) o candidato que ficar em segundo lugar seria indicado para uma vaga ao Senado.

Candidato é Dado, já que remete aos referentes mencionados no cotexto precedente - "Orestes Quércia” e "Michel Temer" - porém traz consigo um elemento Novo, expresso pela oração adjetiva que ficar em segundo lugar.

Também no exemplo abaixo, denúncias que estão no TCU representa um subconjunto (definido pela oração adjetiva restritiva) de "denúncias em geral", mencionadas no co-texto precedente:

(7) Denúncias que estão no TCU foram solicitadas para exame no Planalto.

De modo semelhante, o Tema pode realizar um tipo de Dado que não é um referente presente no co-texto precedente, e sim um referente individualizado a partir de uma classe de referentes anteriormente mencionada. Assim, por exemplo, em

(8) Um ato público está sendo preparado para a semana que vem, em Brasília,

o referente do termo grifado é Novo (o que é sinalizado pelo artigo indefinido), porém a decisão da oposição de organizar vários atos públicos já havia sido referida no co-texto precedente.

O fragmento em (9), abaixo, oferece um exemplo de especificação e individualização progressiva do referente Dado, com VPA sendo empregada, no segundo e no terceiro períodos, para posicionar o Objeto Dado no início da oração. (Ressalve-se, no entanto, que o Tema, no segundo período, é no conflito, e não o Objeto grifado.) 
(9) Os sem-terra estão acampados nas margens do Rio São Miguel, antes de uma ponte que dá acesso à Fazenda Renascença. No conflito, 17 sem-terra foram feridos com balas de borracha e bombas de gás lacrimogêneo. Um deles, Evandro Teixeira da Costa, foi submetido a cirurgia de reconstituição do maxilar (...).

Na seqüência desse fragmento, ocorre mais uma oração em VPA, com o Objeto remetendo ao referente Dado no período anterior (como no exemplo (2), comentado acima):

(10) Ele foi internado no Hospital Nossa Senhora Aparecida, em Arinos.

Inversamente, o Objeto tematizado pode "ampliar" a referência de um elemento Dado, partindo de um evento individual mencionado no cotexto precedente para referir-se a uma classe de eventos, como em

(11) (...) outros nove seqüestros foram registrados na mesma região nos últimos dois meses.

Outro tipo de Dado realizado pelo Objeto tematizado é aquele que pode ser inferido do campo semântico estabelecido pelo co-texto precedente, como em

(12) A unidade de hemodiálise do Real Hospital Português foi interditada ontem (...). Os 312 pacientes foram remanejados para nove clínicas do Recife (...).

$\mathrm{O}$ artigo definido no sintagma os 312 pacientes é um indício de que o termo está sendo tratado como Dado, apesar de não retomar um referente anteriormente mencionado. Trata-se do tipo de Dado caracterizado pela "predizibilidade" e pela "familiaridade assumida" (GÓMEZ-GONZÁLEZ 2000: 57), para cuja inferência é decisivo o conhecimento de mundo do leitor. No entanto, não se trata de Dado apenas situacional, já que existe um vínculo anafórico entre esse termo e o sintagma a unidade de hemodiálise do Real Hospital Português.

O mesmo se dá nos casos abaixo, extraídos da mesma notícia:

(13) (...) o foco da contaminação não foi localizado.

(14) (...) as amostras foram coletadas diariamente. 
Como parte do conhecimento de mundo, assume-se que, se há contaminação (mencionada no co-texto precedente), deve haver um foco; igualmente, se foi feito um exame da água (conforme o co-texto precedente informa) devem ter sido recolhidas amostras.

Mais um exemplo desse tipo de Dado implícito no campo semântico estabelecido pelo co-texto pode ser visto em (15), em que o Objeto grifado pode ser previsto ou inferido a partir da referência anterior à sessão de tortura ocorrida em um presídio. Como em (12), (13) e (14), a presença do artigo definido indica que o termo está sendo apresentado como Dado:

(15) As lesões em 19 detentos foram confirmadas por laudos produzidos por peritos do IML de Sorocaba.

Em 30 ocorrências de VPA no corpus (cerca de 23\%), o Objeto é um referente Novo na progressão temática. Em sete desses casos, isso ocorre no primeiro período da notícia, como nos exemplos abaixo:

(16) O ex-governador Cristovam Buarque (PT) foi condenado ontem pelo juiz Alfeu Machado, da $14^{\mathrm{a}}$ Zona Eleitoral do Distrito Federal, a uma pena de cinco meses de detenção (...)

(17) A unidade de hemodiálise do Real Hospital Português foi interditada ontem pela Secretaria de Saúde de Pernambuco (...)

(18) Na contabilidade oposicionista, só falta uma assinatura para que a CPI da Corrupção seja viabilizada no Senado.

(19) Toda a estratégia de filiação do governador mineiro Itamar Franco ao PMDB foi discutida com o vice-presidente nacional do partido, senador Maguito Vilela (GO).

Nesses casos, a motivação para a opção por VPA não se deve, evidentemente, à tematização de um referente Dado. Em alguns deles, também não se pretendeu, com o emprego de VPA, a omissão dos participantes com função de Agente, expressos no termo agente da passiva em (16) e (17). Está em jogo, portanto, outro tipo de motivação. Pode ser elucidativa a comparação de (16) e (17) com as alternativas hipotéticas em VA:

(16') O juiz Alfeu Machado, da $14^{a}$ Zona Eleitoral do Distrito Federal, condenou ontem o ex-governador Cristovam Buarque (PT) a uma pena de cinco meses de detenção. 
(17’) A Secretaria de Saúde de Pernambuco interditou ontem a unidade de hemodiálise do Real Hospital Português (...)

A comparação sugere que o papel do Tema, em (16) e (17), é "atuar como um orientador para a mensagem veiculada pela oração e para as expectativas do destinatário sobre como compreender o que está por vir" (GÓMEZ-GONZÁLEZ 2000: 97-98). Em outras palavras, pode-se afirmar que o papel do Tema, nesses casos, é indicar que (16) é uma mensagem "sobre" o ex-governador, e não "sobre" o juiz, do mesmo modo que (17) é uma mensagem "sobre" o hospital, e não "sobre" a Secretaria de Saúde ao contrário de (16') e (17'). Mais do que isso, sendo aquelas as primeiras orações nos respectivos textos, seus Temas indicam não apenas do que trata a própria oração, e sim do que trata o texto como um todo, cumprindo, assim, um papel fundamental na orientação cognitiva do leitor.

A propósito de (16) e (17), é relevante recordar a afirmação de THOMPSON (1996: 130), supracitada, de que a tematização de um constituinte particular - no caso do português, o Objeto - é a principal motivação para a escolha da passiva, em especial nos casos em que está presente o constituinte agente da passiva.

Em 23 das ocorrências em que o Objeto equivale a um referente Novo, a oração em causa não se inclui no primeiro período do texto. Em treze delas, o Objeto tematizado cumpre a função de contribuir para a descontinuidade do Tópico do discurso, função essa também reconhecida por GÓMEZ-GONZÁLEZ (2001: 97-98). BLOOR e BLOOR (1995: 6768) observam que uma exceção ao princípio de que a informação nova é apresentada na segunda parte da oração ocorre no início de um novo tópico de conversação ou de uma nova seção de um texto escrito, em que o total da informação é novo.

É significativo observar, porém, que, enquanto o Objeto ocorre posposto ao verbo em apenas duas das 102 orações em que ele representa elemento Dado, a posposição se dá em dez (isto é, cerca de 43\%) das 23 orações em que o Objeto é Novo, não se encontrando no primeiro período do texto, como nos exemplos seguintes:

(20) Ele afirmou que será promovida uma conversa de colegas na Câmara dos Deputados (...) 
(21) Na solenidade, foi lançado o livro Vozes da Oposiz̧ão (...)

(22) (...) uma denúncia em que foram enquadrados, também pelo crime de tortura, o ex-juiz-corregedor dos presídios de Osasco (SP), José Marcos da Silva, dois delegados, um carcereiro e três oficiais da Polícia Militar.

(23) Do conjunto de ações do governo, foram priorizados 50 programas.

A posposição ao verbo coloca o Objeto/Sujeito em posição remática, o que é um recurso para marcar, no texto, informação nova. Nesses casos, VA proveria o mesmo tipo de organização informacional dos constituintes, com o participante Objeto no Rema, com a diferença de que, em VPA com o Sujeito posposto, tem-se uma estrutura marcada, com o verbo na posição temática. Isso contribui para que o foco recaia sobre o elemento Novo - no caso, o Objeto/Sujeito.

Por outro lado, não há nenhum caso de posposição do Objeto/Sujeito nas sete ocorrências em que ele representa elemento Novo no primeiro período da notícia. Embora o número de ocorrências nesse grupo seja pequeno como base para generalizações, o fato sugere que o Tema nãomarcado, nesses casos, tem um papel significativo no estabelecimento do tópico do texto, como se afirmou acima.

A análise das duas únicas ocorrências em que o Objeto Dado é posposto ao verbo permite observar que há uma complexa interação de fatores que interferem na constituição exata da frase. Uma dessas ocorrências é

(24) Na Câmara, onde são exigidas 171 assinaturas, os dados são menos precisos, porque o universo de listas a serem conferidas é maior.

Nesse exemplo, o referente assinaturas é Dado, mas o número delas 171 - é Novo, representando, por isso, uma informação mais relevante, cuja saliência é favorecida pela posição remática. A situação exata, porém, é mais complexa, pois o constituinte sob análise se encontra em oração subordinada. O Tema do período é na Câmara (acompanhado da oração adjetiva), o que representa uma função contrastiva importante, já que a porção anterior do texto descreve as condições prévias para a instalação de CPI no âmbito do Senado. Uma vez que, na oração adjetiva, a posição temática de onde é sistemicamente codificada, o constituinte 171 assinaturas ficaria, de qualquer modo, no Rema. 
A outra ocorrência em que o Objeto Dado se encontra posposto é

(25) Só ontem, depois de intensas negociações, foi superado o veto de Tasso a Machado eJutaby.

Também aqui se encontram diferentes fatores influindo na posposição do Objeto/Sujeito. Por um lado, há a ênfase na circunstância temporal tematizada - realçada, inclusive, por só - marcando a modificação do estado de coisas previamente descrito no texto. Por outro lado, o constituinte 0 veto de Tasso a Machado e Jutaby é relativamente extenso, o que favorece seu posicionamento no final da oração pelo princípio "end wheight", segundo o qual constituintes mais longos são posicionados tardiamente (GÓMEZGONZÁLEZ 2001: 32; ver abaixo).

As motivações apresentadas até aqui para o emprego de VPA correspondem, portanto, à intenção de tematizar o constituinte Objeto, fazendo-o coincidir com o Sujeito, seja porque ele é um elemento Dado no texto, como ocorre na maioria dos casos, e assim contribui para a manutenção do tópico do discurso, seja porque, na minoria dos casos, ele estabelece ou altera o tópico do discurso. Em ambas as situações, cabe a esse Objeto tematizado a função geral de orientar o leitor sobre como compreender o que está por vir.

Outro tipo de motivação para o emprego de VPA liga-se ao foco relativo dado ao Agente. A intenção de ocultar o Agente é clara em muitas das ocorrências que não apresentam o constituinte "agente da passiva". Nesses casos, a opção por VA obrigaria o falante/escritor a mencionar o participante Agente, o que se deseja evitar, seja porque tal participante está claro no contexto (e, assim, sua menção acarretaria redundância), seja porque a identidade específica do Agente é irrelevante ou desconhecida. É o que se observa em algumas das ocorrências examinadas acima, e também nos exemplos seguintes:

(26) Dirceu preferiu não adiantar qual o procedimento político a ser adotado.

(27) Os serviços comunitários deverão ser prestados em uma creche ou em um abrigo para idosos nos finais de semana.

Nessas ocorrências, os respectivos Agentes estão implícitos no co-texto: trata-se do PT, no primeiro caso, e de Cristovam Buarque, no segundo. 
Em (28) e (29), a identidade específica do Agente - "quem enviou o relatório" e "quem gravou o pronunciamento" - é irrelevante em relação ao assunto de cada notícia:

(28) O presidente do Senado garantiu que recebeu do Banco Central apenas um ofício informando que o relatório foi enviado ao Ministério Público do Pará (...)

(29) O pronunciamento foi gravado ontem de manhã no Palácio da Alvorada.

Em (30), a identidade específica do Agente é desconhecida, e a inclusão, na oração em VPA, de um agente da passiva como "pelos criminosos" ou "pelos seqüestradores" seria redundante. No segundo período em (30), fica claro que tal Agente é pressuposto como predizível, segundo sugere o emprego do artigo definido no SN os bandidos:

(30) Ele foi seqüestrado na quarta-feira de manhã quando saía de casa, em Campo Limpo. Os bandidos renderam Jovenildo dentro de sua caminhonete Cherokee e o levaram para o cativeiro (...)

A análise das ocorrências que apresentam agente da passiva revela uma situação mais complexa. A motivação, nesses casos, varia entre o efeito de desfocamento do Agente, apresentado em um plano secundário de importância, e, inversamente, a colocação do Agente em posição focal, em geral no final da oração. É indispensável observar que esses dois efeitos de sentido, aparentemente paradoxais, só podem ser atribuídos às orações em função de seu co-texto específico de ocorrência.

A primeira situação pode ser exemplificada por

(31) Entretanto, foi advertido minutos depois pelo presidente do partido, José Dirceu, de que o próprio Zeca confirmara o convite a dirigentes da legenda.

O Sujeito/Tema elíptico nessa ocorrência é "Lula"5 . A opção por VPA permite tematizar esse participante, mencionado no co-texto anterior, favorecendo a continuidade do tópico, segundo se demonstrou acima. $\mathrm{O}$

\footnotetext{
5 Mais exatamente, essa ocorrência apresenta um Tema múltiplo, formado dos constituintes entretanto - Tema textual - e Lula - Tema topical (cf. HALLIDAY 1994: 52-54). Sobre a condição temática do Sujeito elíptico em português, veja-se GOUVEIA e BARBARA (2000).
} 
Agente "José Dirceu", por sua vez, é relativamente desfocado. A comparação de (31) com sua equivalente hipotética em VA, tendo o presidente do partido, José Dirceu como Sujeito/Tema, permite perceber que a opção por VPA tem o efeito de colocar esse participante em segundo plano:

(31') Entretanto, o presidente do partido, José Dirceu, advertiu-o minutos depois de que o próprio Zeca confirmara o convite a dirigentes da legenda.

No entanto, esse desfocamento não é completo. Embora a informação focal do período - aquela que detém o maior peso informacional no cotexto - seja o teor da advertência (expresso na oração subordinada substantiva, posicionada no final do período), a identidade do Agente é importante em função de sua autoridade institucional, o que reforça a legitimidade da advertência e a fidedignidade da informação prestada. Esse ponto fica claro se (31) for comparada a uma outra alternativa hipotética, sem o agente da passiva:

(31”)Entretanto, foi advertido minutos depois de que o próprio Zeca confirmara o convite a dirigentes da legenda.

É nesse sentido que se pode falar de um "desfocamento relativo" do Agente, o que implica um contínuo em que o Agente se encontra maximamente desfocado nos casos em que é completamente omitido, em VPA sem agente da passiva. Nos casos em que o agente da passiva está presente, VPA pode desfocá-lo em relação à alternativa correspondente em VA, ou servir como uma opção para focalizar mais o Agente, conforme se demonstra abaixo, na análise das ocorrências de (32) a (36).

O corpus examinado confirma o que tem sido apontado em outros trabalhos (p.ex. DUARTE 1992: 19; SHIBATANI 1985: 831): na maioria das ocorrências concretas, VPA aparece sem o constituinte com função sintática de agente da passiva. No presente trabalho, em 132 orações analisadas, apenas 32 - cerca de $24 \%$ - apresentam agente da passiva. Isso confere às orações com agente da passiva uma natureza marcada, isto é: se a forma básica, mais freqüente, dessa construção omite o Agente, sua nãoomissão deve ser especialmente motivada.

Nas notícias examinadas, o agente da passiva, quando ocorre, é posicionado no Rema, o que significa que o foco da oração tende a recair 
sobre ele. Ou seja, se é possível afirmar (como faz SHIBATANI 1985) que a função pragmática precípua da voz passiva é desfocar o Agente, isso só se aplica exatamente às ocorrências que não apresentam o constituinte agente da passiva. Em várias ocorrências desse termo, ele se encontra em posição focal na oração, como resultado de dois tipos básicos de motivação: o Agente é um referente Novo no co-texto, ou é um referente fulcral na orientação argumentativa da oração.

Assim, por exemplo, em

(32) A placa comemorativa foi descerrada por Cabral Filho, Haddad e a neta de Barbosa Lima, Sílvia Barbosa Lima, de 20 anos,

a quantidade de detalhes incluídos no Agente da passiva é, por si, um indício de que se trata de elemento Novo. É sabido que constituintes destinados a introduzir no texto um novo referente tendem a ser mais extensos, a conter mais material lexical. Resulta daí a conjugação dos princípios "end wheight" e "end focus", que subjazem ao "Principle of Functional Sentence Perspective", da Escola de Praga (cf. GÓMEZGONZÁLEZ 2000: 32). O primeiro deles expressa o fato de que a ordem dos constituintes é influenciada por sua extensão: os mais longos tendem a ser posicionados após os mais curtos. Ao mesmo tempo, de acordo com o segundo princípio, o foco informacional da oração tende a recair no final, em geral no último constituinte.

O co-texto que precede (32) trata da cerimônia de descerramento, na ALERJ, de uma placa em homenagem a Barbosa Lima Sobrinho. O Sujeito da passiva - a placa comemorativa - é Dado, nesse ponto do texto (note-se o artigo definido). A oração (32) tem, assim, o papel de introduzir a informação nova - quem descerrou a placa - e, por isso, traz essa informação em posição focal, no final da oração.

O exemplo (32) permite ainda observar que não é exata a correspondência Tema-Dado / Rema-Novo. O Rema, nesse caso, inclui foi descerrada, ou seja, o Processo, já mencionado no co-texto precedente. Isso pode ser descrito em termos da organização que HALLIDAY (1994: 336) chama de "wave-like", com picos de proeminência associados ao início e ao final da oração, conforme a tendência de as informações dadas serem posicionadas antes das informações novas. A noção de foco, definida por 
HALLIDAY (1994: 308) como a “culminância do Novo", é concebida como um contínuo:

(...) Focus is a bierarchical, rather than a discrete notion (i.e. the relatively most salient information) (...) ${ }^{6}$ (GÓMEZ-GONZÁLEZ 2000: 147)

Essa concepção de "saliência relativa" permite descrever adequadamente os fatos observados aqui a respeito de desfocamento/focalização do participante Agente em VPA.

As notícias examinadas incluem outros exemplos em que o agente da passiva corresponde a referente Novo, como

(33) A decisão foi tomada, por unanimidade, pelos presidentes dos cinco tribunais superiores, depois de uma reunião de quase três horas no gabinete do Presidente do Supremo Tribunal Federal (STF), Ministro Carlos Velloso.

As ocorrências em que o Agente detém o foco informacional por ser um referente fulcral na orientação argumentativa da oração aparecem nas notícias em situações de discurso relatado, ou seja, trechos de discurso direto ou indireto correspondentes à transposição, para o texto da notícia, de enunciados produzidos por participantes dos eventos que são objeto da notícia. Esse caso pode ser ilustrado por

(34) Um deles é o seu sobrinho Vander Luís Loubet, secretário de Infraestrutura, que, segundo o governador, foi indicado pelo próprio partido, por ser um militante histórico.

VPA, nesse caso, ocorre em oração subordinada adjetiva. Isso significa que o status temático do Objeto é enfraquecido, uma vez que o pronome relativo ocupa obrigatoriamente a primeira posição oracional, em virtude de restrições sintáticas. Ou seja, a motivação para a opção por VPA, aqui, não é a intenção de tematizar o Objeto, visto que a opção por VA, nesse caso, teria o mesmo efeito, sem resultar em estrutura marcada:

6 (...) o Foco é uma categoria hierárquica, e não uma noção discreta (i.e. a informação relativamente mais saliente) (...) 
(34’ Um deles é o seu sobrinho Vander Luís Loubet, secretário de Infraestrutura, que, segundo o governador, o próprio partido indicou, por ser um militante histórico.

A ocorrência (34) é parte de uma notícia sobre as críticas e sanções sofridas pelo governador Zeca do PT, do Mato Grosso do Sul, por nomear familiares para cargos no governo. Com o agente da passiva em posição final, a oração em exame realça que foi o partido que indicou o sobrinho do governador para determinado cargo (note-se a ênfase de o próprio), o que integra o argumento de auto-defesa do governador, baseado na competência dos nomeados. Uma paráfrase de (34) adequada ao co-texto seria

(34")Um deles é o seu sobrinho Vander Luís Loubet, secretário de Infraestrutura, que, segundo o governador, foi o próprio partido que indicou, por ser um militante histórico.

A marca sintática foi...que tem o efeito de fazer recair o foco sobre 0 próprio partido, o que se consegue em (34) com a opção por VPA com o agente da passiva no final da oração.

Outra ocorrência interessante é

(35) “(...) nunca a esquerda foi dirigida por gente tão desqualificada (...)”

A intenção dessa oração no co-texto é precisamente a crítica à direção da esquerda brasileira (mais especificamente, a Lula) feita por um exintegrante do PT. A comparação com as alternativas hipotéticas, abaixo, permite perceber mais claramente a incidência do foco sobre o agente da passiva:

(35') Nunca a esquerda foi dirigida.

(35”)Nunca gente tão desqualificada dirigiu a esquerda.

Em (35'), observa-se a mudança de sentido em relação à oração original - o novo significado seria algo como "a esquerda nunca recebeu direção". Em (35”), o conteúdo proposicional é o mesmo de (35), porém a ênfase no Agente não é tão nítida. 
Em (36), abaixo, também é evidente o foco no Agente:

(36) “(...) a maioria dos fatos listados ou são do passado ou estão sendo investigados pelos canais regulares, democráticos e competentes."

Trata-se de transcrição de fala do porta-voz da Presidência da República, argumentando contra a abertura de CPI para investigar denúncias de corrupção. O argumento, nessa frase, é o de que a CPI não é necessária porque os fatos em questão já estão sendo investigados em outras instâncias - que não são, no entanto, identificadas. À imprecisão semântica do substantivo canais, junta-se a forte carga emocional da extensa adjetivação - regulares, democráticos e competentes - e se consegue-se que o foco recaia sobre esse sintagma colocando-o na posição oracional final. O resultado é um conjunto de recursos voltados para a intenção argumentativa do falante.

$\mathrm{Da}$ análise exposta, pode-se concluir que as orações em VPA, ao tematizarem o Objeto, realizam uma dupla função. Por um lado, o Objeto convertido em Tema desempenha um papel crucial no estabelecimento, na manutenção e na alteração do tópico do discurso. Por outro lado, essa tematização, ao desvincular a função de Agente das de Tema e Sujeito, permite variar o grau de focalização conferido ao Agente.

O potencial para o desfocamento do Agente relaciona-se à propriedade sintático-semântica de VPA de, promovendo o Objeto à condição de Sujeito, tornar possível a expressão do processo sem a menção do Agente, que seria obrigatória na alternativa equivalente em VA. Assim sendo, esse desfocamento é maximamente obtido quando a oração não inclui o constituinte agente da passiva.

A possibilidade de focalizar o Agente, por sua vez, está relacionada à conversão do Objeto em Tema, já que uma das tarefas do Tema é justamente "ajudar (negativamente) a construir a proeminência discursiva de itens (posicionar um item tardiamente em uma oração confere a ele o status de informação nova)" (GÓMEZ-GONZÁLEZ 2000: 97-98). Em síntese, é possível constatar, nas ocorrências examinadas, as razões apontadas por HALLIDAY (1994: 169) para a escolha da voz passiva em inglês: 
The reasons for choosing passive are as follows: (1) to get the Medium as Subject, and therefore as unmarked Theme ('I'm telling you about the glass' (no exemplo em exame: 'the glass was broken by the cat'\}); and (2) to make the Agent either (i) late news, by putting it last ('culprit: the cat'), or (ii) implicit, by leaving it out. ${ }^{7}$

\section{VPS: A tematização do Processo}

Como o primeiro constituinte oracional em VPS, na ordem nãomarcada, não é o Objeto, e sim o verbo (Predicador/Processo), essa construção não se presta idealmente a preencher a função reconhecida acima para VPA - a de permitir a tematização do participante Objeto, contribuindo para a progressão da referência ao longo do texto. De fato, o exame do corpus revela que, ao contrário do que se observa para VPA, o Objeto de VPS corresponde a Dado apenas na minoria das ocorrências (em cerca de $27 \%$, o equivalente a 32 delas), como se afirmou na Introdução. Tem-se aqui, portanto, uma relevante diferença de significado entre as duas estruturas, uma vez que se entenda o significado não apenas como o "conteúdo" ideacional, mas também em suas dimensões textual e interpessoal, segundo os pressupostos sistêmico-funcionais.

Um exame mais detalhado dos casos de Objeto Dado com VPS revela que em somente 12 das 32 ocorrências o Objeto aparece anteposto ao verbo. Em sete delas, a anteposição se deve ao fato de que VPS está em oração adjetiva, sendo o Objeto representado por pronome relativo - sua anteposição, portanto, é obrigatória, como se observou na seção 2. Tal pronome, também por força de codificação sintática inscrita no sistema, corresponde necessariamente a Dado, visto que sempre retoma anaforicamente um SN da oração principal, ou seja, do co-texto imediatamente precedente, como nos exemplos abaixo:

(37) Faltou aos vestibulandos da democracia alguma coisa que só se adquire no ofício do possível, que é o limite da política.

\footnotetext{
7 As razões para escolher a passiva são as seguintes: (1) colocar o Meio como Sujeito e, portanto, como Tema não-marcado ("estou lhe falando do copo" [no exemplo em exame: "o copo foi quebrado pelo gato"] ); e (2) tornar o Agente ou (i) informação tardia, colocando-o por último ("culpado: o gato"), ou (ii) implícito, deixando-o de fora.
} 
(38) Qual a explicação para a chocante diferença entre regiões tão assemelhadas no clima, nas altitudes médias, nas temperaturas e, principalmente, na beleza natural que lá se preserva e aqui se destrói com a complacência, a omissão e o estímulo dos políticos de todos os partidos?

(39) "Nacionalista, atrasado, antiprivatista, ressentido, mercurial", foi o mínimo que se disse dele.

Devido a essa obrigatoriedade da anteposição do Objeto representado pelo pronome relativo, duas das ocorrências analisadas apresentam ambigüidade entre o sentido "evento espontâneo" (em que a ordem não marcada é SN V), e o sentido "sujeito indeterminado" (em que a ordem não-marcada é V SN ${ }^{8}$ :

(40) (...) calúnia que se espalhou à vontade durante o reinado de FH?

(41) Na herança do octanato, poderia ainda, no lusco-fusco da transição, anteciparse o deslinde de outro racha, que não se esconde debaixo do tapete.

Há, portanto, somente cinco ocorrências com Objeto Dado anteposto em que se pode afirmar que o autor do texto optou pela anteposição:

(42) Na década de 90, o Brasil queimou etapas na maioria dos parâmetros que se referem à educação. É $o$ que se depreende da Síntese dos Indicadores Sociais que o IBGE acaba de divulgar.

(43) (...) cresce cada vez mais o número de famílias cujo sustento está nas mãos de mulheres. Isso se verifica principalmente nas famílias de baixa renda.

(44) (...) a responsabilidade de escolher governantes não precisa da intolerância, mas da permanente vigilância. E esta não se faz mediante denuncismo que, antes de apurado cada caso, não passa a outro.

(45) O Estado está aí mais para arcar com prejuízos do que para obter lucros. Prejuízos dividem-se entre todos, lucros não.

(46) As copas não se explicam politicamente.

8 No sentido "evento espontâneo" das construções com se, um Processo é representado como ocorrendo sem um participante causador, ou seja, sem um Agente. No sentido "sujeito indeterminado", a existência do Agente é reconhecida, apenas não se apresenta sua identidade. 
Em (45), é claro o caráter marcado da anteposição do Objeto prejuízos, com valor contrastivo. Em (43) e (46), a anteposição de isso e de as copas não parece portar a carga semântica de ordem marcada. Parece evidenciarse, nesses exemplos, o "sentido potencial" (SHIBATANI 1985) - paráfrases adequadas de tais orações seriam, por exemplo, isso pode ser verificado / isso é verificável e as copas não podem ser explicadas / as copas não são explicáveis.

Na maioria dos casos em que o Objeto é Dado, ele se encontra posposto ao verbo, de acordo com a ordem não-marcada em VPS, como nos exemplos abaixo. Em (47), o Protocolo se refere ao Protocolo de Kyoto, já mencionado em segmentos anteriores do texto; em (48), a luta diz respeito ao trabalho da prefeitura de Gramado, caracterizado no período anterior como a batalha pela preservação do meio ambiente.

(47) Com a posição de Bush, os EUA rompem seu compromiso original na Convenção do Clima, pois a decisão resultante da Conferência Rio 92 foi modificada em Kyoto, e uma vez que não se cumpra o Protocolo, a Convenção torna-se inócua.

(48) Para deter a degradação, amplia-se a luta em todas as frentes.

A motivação para a opção por VPS não se explica, portanto, pela necessidade de colocar na primeira posição oracional o Objeto Dado, ao contrário do que se pode observar no caso de VPA. No que diz respeito ao componente textual dessa motivação, a comparação de (47) e (48) com suas respectivas alternativas hipotéticas pode ser elucidativa:

(47’) (...) uma vez que o Protocolo não seja cumprido, a Convenção torna-se inócua.

(48') Para deter a degradação, a luta é ampliada em todas as frentes.

Em princípio, (47’) e (48') seriam aceitáveis nos co-textos de (47) e (48). No entanto, a forma efetivamente empregada pelos autores, ao tematizar o Processo, e não o Objeto, enfatiza a atividade nos estados de coisas representados, e não a passividade. Essa opção é perfeitamente condizente com o objetivo central de cada um dos textos. No primeiro caso, o autor critica a atitude do governo norte-americano, que se recusa a acatar o Protocolo de Kyoto, com grave prejuízo da preservação ambiental. No segundo, o autor elogia as medidas tomadas pelo governo municipal de Gramado em favor do meio ambiente. Em ambos os casos, portanto, 
são as ações que estão sendo prioritariamente enfocadas. A ordem nãomarcada V SN em VPS favorece a tematização do Processo, o que pode ter função de relevo no desenvolvimento do texto, como sugerem os exemplos (47) e (48).

Em algumas das ocorrências, o Objeto posposto inclui material novo junto a algum elemento que pode ser considerado Dado. Em (49), abaixo, por exemplo, a figura do primeiro-ministro remete, anaforicamente, a o cargo que fazia falta:

(49) De tanta conversa primeiro com um e depois com os outros, a função gerou o cargo que fazia falta e assim se esboçou, sem injunção da teoria, a figura do primeiro-ministro como intermediário entre o monarca e o gabinete.

O SN a figura do primeiro-ministro, porém, não representa simples remissão anafórica, mas serve principalmente para nomear e, dessa forma, sintetizar o conceito em questão, que foi primeiramente analisado em termos do desenvolvimento histórico de seu papel político.

As duas ocorrências seguintes são semelhantes a essa no sentido de que o Objeto de VPS, em cada caso, é uma retomada anafórica de algo mencionado no co-texto precedente, porém sua contribuição mais importante para o desenvolvimento do texto não é a mera remissão, e sim a carga de conteúdo semântico novo acrescentado que, em última análise, representa uma avaliação ou um julgamento feito pelo autor. Assim, em (50), o diagnóstico oficial sintetiza uma explanação extensa apresentada no co-texto precedente, ocupando toda a segunda metade do parágrafo anterior. Ao sintetizar, a expressão referencial também "rotula", ou seja, classifica e qualifica a referida explanação como "diagnóstico" e como "oficial":

(50) Mesmo que se aceite o diagnóstico oficial, não há como fugir à impressão de que o governo corre o risco de trocar seis por meia dúzia ao insistir numa bolsa administrada.

Em (51), o longo SN cujo núcleo é obstáculo não apenas remete ao referente Lei de Segurança Nacional, previamente mencionado, mas principalmente expressa a opinião do autor, em termos de julgamento e avaliação, sobre o significado histórico-político da referida lei: 
(51) Está com o Presidente da República e chegará ao Senado por estes dias (...) o projeto de extinção da famigerada Lei de Segurança Nacional (...) Remove-se um obstáculo histórico erigido em caráter jurídico excepcional e mantido, por medo da liberdade e da responsabilidade, nos períodos constitucionais.

Na ocorrência (52), o Objeto de VPS é representado pela oração que muitos criminosos podem, efetivamente, ser irrecuperáveis. Trata-se de Dado, visto que retoma idéia expressa no período anterior:

(52) Além disso, o pressuposto da proposta de pena de morte é que o criminoso é irrecuperável. Admitindo-se que muitos criminosos podem, efetivamente, ser irrecuperáveis, a questão é decidir se os que não são devem ser sacrificados em nome do princípio da punição irrevogável.

No entanto, ao ser retomada no segundo período do fragmento transcrito, a oração que o criminoso é irrecuperável recebe o acréscimo de elementos modalizadores, que diminuem o grau de assertividade da proposição (muitos... podem, efetivamente). Dessa forma, se, por um lado, a oração que preenche a função de Objeto de VPS representa elemento Dado porque retoma idéia do co-texto precedente, evidencia-se, por outro lado, seu papel na transição para uma idéia nova, como parte de uma estratégia argumentativa de concordância parcial: o autor reconhece parcialmente a validade do argumento que pretende combater para, em seguida, questioná-lo em um ponto mais essencial.

A construção em VPA correspondente ao exemplo ora examinado soa muito artificial, podendo-se levantar dúvidas quanto a sua aceitabilidade:

(52”)Sendo admitido que muitos criminosos podem, efetivamente, ser irrecuperáveis, a questão é decidir se os que não são devem ser sacrificados em nome do princípio da punição irrevogável.

O corpus não inclui nenhuma ocorrência em que o Sujeito de VPA seja oracional. Entre as ocorrências de VPS, porém, há muitos períodos em que o Complemento é uma oração. É interessante relacionar esse fato à afirmação supracitada de THOMPSON (1996: 170), segundo a qual informação nova é normalmente introduzida no texto por orações. De fato, praticamente todos os casos encontrados de Complemento oracional com VPS representam introdução de informação nova - seja em orações desenvolvidas, como em (53) e (54), seja em reduzidas, como em (55) e (56) - ainda que em algumas das ocorrências, como por exemplo (54), essas orações incluam um referente Dado: 
(53) Não se vai esperar que um homem atrás das grades, tratado como um animal, vilipendiado, explorado, venha espontaneamente inclinar-se para valores humanos superiores.

(54) Em 1997, quando já se via que não seria cumprida a meta da Convenção do Clima, foi deliberado o Protocolo de Kyoto (...)

(55) (...) decidiu-se realizar um ciclo de três debates (...)

(56) (...) evita-se nomear parentes (...)

\section{Conclusão}

Em síntese, a análise do corpus revela que a escolha léxico-gramatical disponível para o falante do português entre VPA e VPS apresenta-se como alternativas para a realização de diferentes significados no nível da metafunção textual. Mais exatamente, essas duas configurações, além de VA, contribuem de modo diferente para o fluxo informacional do texto, visto que informação dada tende a ser codificada na primeira posição oracional, e que picos de proeminência estão associados ao início e ao final da oração.

Uma vez que, em VPA, a ordem não-marcada é SN V, essa estrutura se presta adequadamente à tematização do participante paciente do processo verbal. Nas notícias jornalísticas examinadas, essa tematização serve, na maioria dos casos, para posicionar um referente Dado no início da oração. Em VPS, ao contrário, a ordem não-marcada é V SN - o constituinte tematizado é, portanto, o Processo, e não qualquer dos participantes.

Dentro da concepção tridimensional do significado proposta pela abordagem sistêmico-funcional, é possível identificar diferenças semânticas entre as duas estruturas examinadas. Uma concepção do significado limitada ao âmbito ideacional tenderá a ver sinonímia nesse caso, já que ambas as construções permitem a representação de um Processo sem a identificação do Agente. É provavelmente por essa razão que a gramática tradicional, em especial após a NGB, tem insistido na equivalência semântica entre as duas construções. Na perspectiva aqui adotada, não apenas o significado inclui os componentes textual e interpessoal, ao lado do ideacional, como também a funcionalidade dos elementos léxico-gramaticais é vista como incorporada ao próprio significado. Desse modo, pode-se lançar luz sobre aspectos da questão que têm escapado a outras abordagens. 
Cumpre ressalvar, finalmente, que o corpus examinado foi limitado no que diz respeito aos gêneros textuais incluídos. O estudo dos fatos aqui levantados em outros tipos de textos forneceria uma base mais ampla para as generalizações propostas.

E-mail: hfhawad@hotmail.com

Recebido em novembro de 2003

Aprovado em fevereiro de 2004

\section{REFERÊNCIAS Bibliográficas}

BloOr, Thomas e Meriel BLOOR. 1995. The Functional Anlysis of EnglishA Hallidayan Approach. London: Arnold.

Duarte, Yara Conceição M. A. 1992. Portuguese and English Passives in Contrast. Estudos Anglo-Americanos 16: 19-31.

Gómez-GonzÁlez, María Ángeles. 2001. The Theme-Topic Interface: Evidence from English. Amsterdam/Philadelphia: John Benjamins.

Gouveia, Carlos A. M. e Leila BARBARA. 2000. Marked or unmarked that is NOT the question, the question is: Where's the Theme? Paper presented at the $12^{\text {th }}$ Euro-International Systemic Functional Linguistics Workshop. University of Glasgow, 19-22 July 2000.

Halliday, Michael A. K. 1994. An Introduction to Functional Grammar. London: Edward Arnold.

Hawad, Helena Feres. 1999. Funções Discursivas da Voz Passiva e da Indeterminação do Sujeito. Monografia. Inédito. . 2002. Tema, Sujeito e Agente: A Voz Passiva Portuguesa em Perspectiva Sistêmico-Funcional. Tese de Doutorado - Departamento de Letras, Pontifícia Universidade Católica do Rio de Janeiro.

Kopple, William J. Vande. 1986. Given and New Information and Some Aspects of the Structures, Semantics and Pragmatics of Written Texts. In: Charles R. Cooper e Sidney Greenbaum (eds.) 1986. Studying Writing - Linguistic Approaches. London: Sage Publications: 72-111.

Neves, Maria Helena de Moura. 2000. Gramática de Usos do Português. São Paulo: UNESP.

Perini, Mário Alberto. 1985. Para uma Nova Gramática do Português. São Paulo: Ática.

Shibatani, Masayoshi. 1985. Passives and Related Constructions: A Prototype Analysis. Language 61.4: 821-848.

Thompson, Geoff. 1996. Introducing Functional Grammar. London: Arnold. 